\title{
Por que os gram-negativos ainda predominam como causa de infecção bacteriana nos pacientes hematológicos no Brasil
}

\section{Why gram-negative bacteria are the major cause of bacterial infection among hematology patients in Brazil}

\section{Silvia F. Costa}

Já na década de 70 foi demonstrado que o uso empírico de antibiótico com ação contra gram-negativos era essencial na condução da febre de origem indeterminada em pacientes neutropênicos. ${ }^{1,2}$ Casuísticas americanas e européias de infecção em pacientes hematológicos publicadas mais recentemente evidenciaram mudança no perfil das infecções bacterianas nos pacientes neutropênicos, ocorrendo um aumento das infecções causadas por bactérias gram-positivas na última década. ${ }^{1,3}$ Esta mudança é multifatorial e está associada ao tipo de quimioterapia mieloablativa utilizada no tratamento das doenças hematológicas, ao uso cada vez mais frequente de dispositivos invasivos e também ao uso de profilaxia com quinolona, particularmente ciprofloxacina, que aumenta o risco de infecção por Streptococus viridans. ${ }^{1,3}$

Dados nacionais mostram, entretanto, que os gramnegativos ainda são os vilões das infecções bacterianas em pacientes hematológicos em alguns hospitais brasileiros. ${ }^{4,5}$ $O$ presente estudo de Gabe et $a l^{6}$ publicado neste volume da Revista Brasileira de Hematologia e Hemoterapia também evidenciou que as bactérias são as principais causas de infecção no pacientes pediátricos com leucemia, correspondendo a $52 \%$ das infecções, ocorrendo predomínio de gramnegativos, particularmente E. coli e P.aeruginosa. Já os parasitas, os vírus e os fungos representaram respectivamente apenas $20,6 \%, 15 \%$ e $7,9 \%$ das infecções.

Algumas hipóteses podem explicar este fato. O predomínio de gram-negativos nesta população pode ser apenas o reflexo da alta incidência de infecção de corrente sanguínea relacionada à assistência a saúde causada por gram-negativos nos vários centros brasileiros. ${ }^{7}$ Dados de estudos internacionais mostram que alguns gram-negativos como Acinetobacter spp. e P. aeruginosa têm caráter sazonal, e, portanto, incidência aumentada durante o verão. ${ }^{8}$ Sendo um país tropical, este fato poderia explicar a alta prevalência deste agente em hospitais brasileiros. Outros fatores que também podem contribuir para baixa prevalência de gram-positivos no país é a baixa prevalência de infecções por Enterococcus resistente à vancomicina que é um dos principais agentes de infecções de corrente sanguínea em hospitais americanos e europeus, ${ }^{9}$ assim como a baixa aderência dos centros brasileiros ao uso de profilaxia antibiótica com quinolona nos pacientes neutropênicos.
Herpes simplex e varicela zoster são as principais causas de infecções virais em pacientes leucêmicos pediátricos. ${ }^{10}$ A incidência de doença citomegálica, entretanto, é bastante variável. No presente estudo, citomegalovírus foi diagnosticado apenas em dois pacientes. A baixa prevalência de doença citomegálica em casuísticas nacionais pode ser decorrente da dificuldade do diagnóstico definitivo de doença por este agente.

Candida spp. foi o principal fungo identificado no estudo de Gabe et al. ${ }^{6}$ Infelizmente, estes autores não identificaram a espécie da Candida. Estudos conduzidos em centros que utilizam profilaxia primária com azólicos mostram que pode haver, provavelmente devido à pressão seletiva do uso de antifúngico, aumento de espécies não albicans como causa de infecção em pacientes com leucemia. ${ }^{11,12}$

Poucos são os dados nacionais de estudos de parasitose em pacientes com leucemia. ${ }^{13}$ Ascaris lumbricoides foi o principal parasita encontrado nas crianças com leucemia no estudo de Gabe et al., entretanto, não fica claro qual é a conduta do serviço no que diz respeito a investigação destes agentes, não foi descrita a indicação, frequência e número de parasitológicos de fezes realizados.

Apesar de retrospectivo, o estudo de Gabe et al. é uma casuística nacional de infecções em pacientes pediátricos com leucemia, que pode ser útil para tomada de conduta local e servir de inspiração para realização de outros estudos brasileiros.

\section{Referências Bibliográficas}

1. Hughes WT, Armstrong D, Bodey GP, Bow EJ, Brown AE, Calandra T, et al. 2002 guidelines for the use of antimicrobial agents in neutropenic patients with cancer. Clin Infect Dis. 2002; 34 (6): $730-51$.

2. Sickles EA, Greene WH, Wiernik PH. Clinical presentation of infection in granulocytopenic patients. Arch Intern Med. 1975 May;135(5):715-9.

3. Rubio M, Palau L, Vivas JR, del Potro E, Diaz-Mediavilla J, Alvarez A, et al. Predominance of gram-positive microorganisms as a cause of septicemia in patients with hematological malignancies. Infect Control Hosp Epidemiol. 1994;15(2):101-4.

4. Velasco E, Byington R, Martins CA, Schirmer M, Dias LM, Gonçalves VM. Comparative study of clinical characteristics of neutropenic and non-neutropenic adult cancer patients with bloodstream infections. Eur J Clin Microbiol Infect Dis. 2006; 25(1):1-7.

5. Velasco E, Byington R, Martins CA, Schirmer M, Dias LM, Gonçalves VM. Prospective evaluation of the epidemiology, microbiology, and outcome of bloodstream infections in hematologic patients in a single cancer center. Eur J Clin Microbiol Infect Dis. 2003; 22 (3): $137-43$.

6. Gabe C, Almeida DR, Siqueira LO. Avaliação de eventos infecciosos oportunistas em crianças portadoras de leucemias. Rev. Bras. Hematol. Hemoter. 2009;31(2):74-79.

7. Girão E, Levin AS, Basso M, Gobara S, Gomes LB, Medeiros EA, et al. Trends and outcome of 1121 nosocomial bloodstream infections in intensive care units in a Brazilian hospital, 19992003. Int J Infect Dis. 2008;12(6):e145-6.

8. Perencevich EN, McGregor JC, Shardell M, Furuno JP, Harris AD, Morris JG Jr, et al. Summer Peaks in the Incidences of Gram- 
Negative Bacterial Infection Among Hospitalized Patients. Infect Control Hosp Epidemiol. 2008;29(12):1124-31.

9. Low DE, Keller N, Barth A, Jones RN. Clinical prevalence, antimicrobial susceptibility, and geographic resistance patterns of enterococci: results from the SENTRY Antimicrobial Surveillance Program, 1997-1999. Clin Infect Dis. 2001;32 Suppl 2:S133-45

10. Pagano L, Caira M, Candoni A, Offidani M, Fianchi L, Martino B, et al. The epidemiology of fungal infections in patients with hematologic malignancies: the SEIFEM-2004 study. Haematologica. 2006;91(8):1068-75.

11. Kaya Z, Gursel T, Kocak U, Aral YZ, Kalkanci A, Albayrak M. Invasive fungal infections in pediatric leukemia patients receiving fluconazole prophylaxis. Pediatr Blood Cancer. 2009; 52(4):470-5

12. Loutfy SA, Alam El-Din HM, Ibrahim MF, Hafez MM. Seroprevalence of herpes simplex virus types 1 and 2, Epstein-Barr virus, and cytomegalovirus in children with acute lymphoblastic leukemia in Egypt. Saudi Med J. 2006;27(8):1139-45.

13. Schaffel R, Nucci M, Carvalho E, Braga M, Almeida L, Portugal R, et al. The value of an immunoenzymatic test (enzyme-linked immunosorbent assay) for the diagnosis of strongyloidiasis in patients immunosuppressed by hematologic malignancies. Am J Trop Med Hyg. 2001;65(4):346-50.

Avaliação: O tema abordado foi sugerido e avaliado pelo editor.

Recebido: 26/02/2009

Aceito: $02 / 03 / 2009$

${ }^{1}$ Médica do grupo de imunodeprimido da Faculdade de Medicina da Universidade de São Paulo

Correspondência: Silvia Figueiredo Costa

Av. Dr. Enéas Carvalho de Aguiar $n^{\circ} 470$

Instituto de Medicina Tropical, Prédio 2, $1^{\circ}$ andar, sala 112

Cerqueira César

05403-000 - São Paulo-SP 